Article

\title{
Interspecific Association and Community Stability of Tree Species in Natural Secondary Forests at Different Altitude Gradients in the Southern Taihang Mountains
}

\author{
Shan-Shan Jin ${ }^{\dagger}$, Yan-Yan Zhang ${ }^{+}{ }^{\mathbb{D}}$, Meng-Li Zhou, Xiao-Ming Dong, Chen-Hao Chang, Ting Wang \\ and Dong-Feng Yan *
}

Citation: Jin, S.-S.; Zhang, Y.-Y.; Zhou, M.-L.; Dong, X.-M.; Chang,

C.-H.; Wang, T.; Yan, D.-F.

Interspecific Association and Community Stability of Tree Species in Natural Secondary Forests at Different Altitude Gradients in the Southern Taihang Mountains. Forests 2022, 13, 373. https://doi.org/ 10.3390/f13030373

Academic Editors: Runguo Zang and Yi Ding

Received: 23 December 2021

Accepted: 21 February 2022

Published: 23 February 2022

Publisher's Note: MDPI stays neutral with regard to jurisdictional claims in published maps and institutional affiliations.

Copyright: (c) 2022 by the authors. Licensee MDPI, Basel, Switzerland. This article is an open access article distributed under the terms and conditions of the Creative Commons Attribution (CC BY) license (https:// creativecommons.org/licenses/by/ $4.0 /)$.
College of Forestry, Henan Agricultural University, Zhengzhou 450002, China; jinshanshanzzz@126.com (S.-S.J.); zyylxyhenau@126.com (Y.-Y.Z.); dreamer170808@126.com (M.-L.Z.); dxm13592503501@126.com (X.-M.D.); changchenhao2022@163.com (C.-H.C.); tingwang126@126.com (T.W.)

* Correspondence: ydflx@henau.edu.cn

+ These authors contributed equally to this work.
Abstract: An interspecific association represents an inter-relatedness of different species in spatial distribution and combined with the altitude factor, is key for revealing the formation and evolution of an ecological community. Therefore, we analyzed the changes in interspecific association and community stability at different altitudes in the southern Taihang Mountains using the variance ratio $(V R), \chi^{2}$ test, association coefficient $(A C)$, percentage of co-occurrence $(P C)$ and Godron stability method. In total, 27 sample plots measuring $20 \times 20 \mathrm{~m}$ were set up and were divided into lower altitude (700 1100 m), medium altitude (1100 1500 m) and higher altitude areas (1500 1900 m) into. The results showed that the overall interspecies association of communities exhibited an insignificant negative association in both the lower $(V R=0.79, W=7.15)$ and higher $(V R=0.81, W=7.36)$ altitude areas, while an insignificant positive association was observed in the medium $(V R=1.48, W=13.34)$ altitude area. Besides, the $\chi^{2}$ test showed the ratio of positively and negatively correlated species pairs decreased as altitude increased with values of $1.39,1.22$ and 0.95 in the lower, medium and higher altitude areas, respectively. Moreover, the $A C$ and $P C$ indices stated that most species pairs had a weaker association in the three altitude areas, but the $A C$ indices also suggested the number of positive association species pairs was more than that of negative association only in medium altitude area. Meanwhile, the Godron stability method showed the distances from the intersection point to the stable point (20 and 80) were still far away, with values of 22.53, 11.92 and 21.34 in the lower, medium and higher altitude areas, respectively, which indicated an unstable succession stage, though the community appeared steadier in the medium altitude area. This study can provide some guidance for effective afforestation and vegetation restoration.

Keywords: altitude; interspecific association; Godron stability; the southern Taihang Mountains

\section{Introduction}

Tree species are interdependent in the forest successional process, with a greatly changed abundance and composition, which showed a certain interspecific association and then affected the forest stability [1-4]. This interspecific association represents an inter-relatedness of different species in the spatial distribution affected by different habitats of tree populations and is essential for the formation and evolution of ecological communities [5-7], so it can be generally reflected by their corresponding habitats $[8,9]$. Additionally, interspecific association is mainly used to explain the community composition, structure, function, succession trend and competition status $[10,11]$. Therefore, relevant studies on interspecific association can provide an important scientific and theoretical basis for vegetation reconstruction and biodiversity protection. 
Community stability is a foundation for the continuous functioning of the forest ecosystem and has a comprehensive feature of the structure and function of the plant community [12]. Generally, the biological ecology method and the Godron stability measurement method were used to describe the community stability in previous studies. The former is mainly analyzed by using tree species compositions and community age structures, and the latter is reflected by the means of mathematical models [13]. In this study, we selected the second method, in view of the actual situation of the study area. Community stability and interspecific association are usually combined to reveal the competition status of plant populations, community structure and the trend of community succession [14-16].

Altitude greatly influenced species distribution and forest stability and was the main terrain factor [17-20]. For example, Zhang et al. [17] considered the vegetation patterns in the middle part of the Taihang Mountain Range to be significantly correlated with altitude, $\mathrm{Mu}$ et al. [21] found a higher continuity existed along an altitudinal gradient in the secondary forest community in Changbai Mountains and Cabrera et al. [22] showed that altitude was responsible for the division of structural and floristic groups, as the most important factor for analyzing the diversity and structure of the vanishing montane forest of southern Ecuador. Besides, Bhutia et al. [23] suggested that low-altitude forests (900-1700 $\mathrm{m}$ ) had the highest Shannon diversity index by examining the forest structure in the eastern Himalayas. These examples demonstrate that previous studies on forest communities principally focused on the relationships between altitude and species diversity or distribution. Moreover, researches on interspecific relationships are mostly conducted under a similar habitat condition, such as at a same altitude level [17,21-23]. However, there are few studies that have linked altitude factors with interspecies associations and community stability and analyzed their interactions.

The Taihang Mountains are located at the intersection of the north and south flora, with abundant species and a complex community structure [24]. However, the forests in this area are subject to frequent human disturbances and suffered severe soil erosion since the 1950s, resulting in heavy habitat destruction and biodiversity loss, as well as poor ecosystem self-recovery capabilities $[25,26]$, but vegetation there is gradually recovering, with a series of natural forest protection and reconstruction projects in recent years [27]. Therefore, the study of vegetation restoration in this area has become a hot topic today. For example, Yan et al. [28] analyzed the niche characteristics of tree populations at different altitudes, Zhao et al. [26] revealed the relationship between secondary forests and environment and Zhao et al. [29] explored the mechanism of plant community diversity changes. Moreover, it is of great significance to study the relationship between different altitudes and interspecies association and the community stability of the dominant tree species in this area, but relevant research is still rare.

It is necessary to explore the current state and regularity of the interspecific association and community stability at different altitudes in this local area, which is important for formulating protection policies of species diversity and forest conservation. Therefore, we aim to answer the following questions in this study: (1) As altitude changes, has the interspecific association changed significantly? (2) Has altitude change affected vegetation community stability? (3) What is the current stage of vegetation succession in this area?

\section{Materials and Methods}

\subsection{Location Overview of Study Area}

The Taihang Mountains are located on the eastern border of the Loess Plateau. They belong to a typical mountainous landform and an important ecological barrier for the North China Plain. The study area was located in the southern Taihang Mountains in northern Jiyuan City, Henan Province (Figure 1). The climate here was warm temperate and semi-humid, with the continental characteristic of a mean annual temperature of $14.5^{\circ} \mathrm{C}$. The annual sunshine duration is $20,400 \mathrm{~h}$, the frost-free period is 213 days, and the annual rainfall is $696 \mathrm{~mm}$, which mainly falls from July to September [30]. The altitude ranges from $150 \mathrm{~m}$ to $1955 \mathrm{~m}$. The Taihang Mountains are highly heterogeneous in terms 
of topography, soil, climate and vegetation due to the wide range of altitude and typical geological features [20]. The landform in this region is mostly hilly and mountainous, and the soil type belongs to brown and cinnamon soil, which is mostly acid and neutral. In 1998, the Taihang Mountain Macaque Nature Reserve was set up in the southern Taihang Mountains to protect the local forest ecosystem. At present, most forests in this area are relatively young, and most of the areas below $600 \mathrm{~m}$ above sea level grow secondary forests, shrubs and cultivated land, while primary secondary forests distribute widely above $600 \mathrm{~m}$ above sea level. The main vegetation types there are secondary broadleaved deciduous forests (including the tree species Quercus aliena, Quercus variabilis, Cotinus coggygria, etc.), the shrubs are mostly Vitex negundo var. heterophylla and Viburnum mongolicum and the grasses are mostly Elsholtzia ciliate and Carex rigescens [28]. In this field, we found there are fewer newer seedlings under the forest and the shrubs are mostly Viburnum dilatatum, Forsythia suspensa, Vitex negundo var. Heterophylla., etc. Carex rigescens, Clematis florida and Elsholtzia ciliate distribute widely in grass layer.
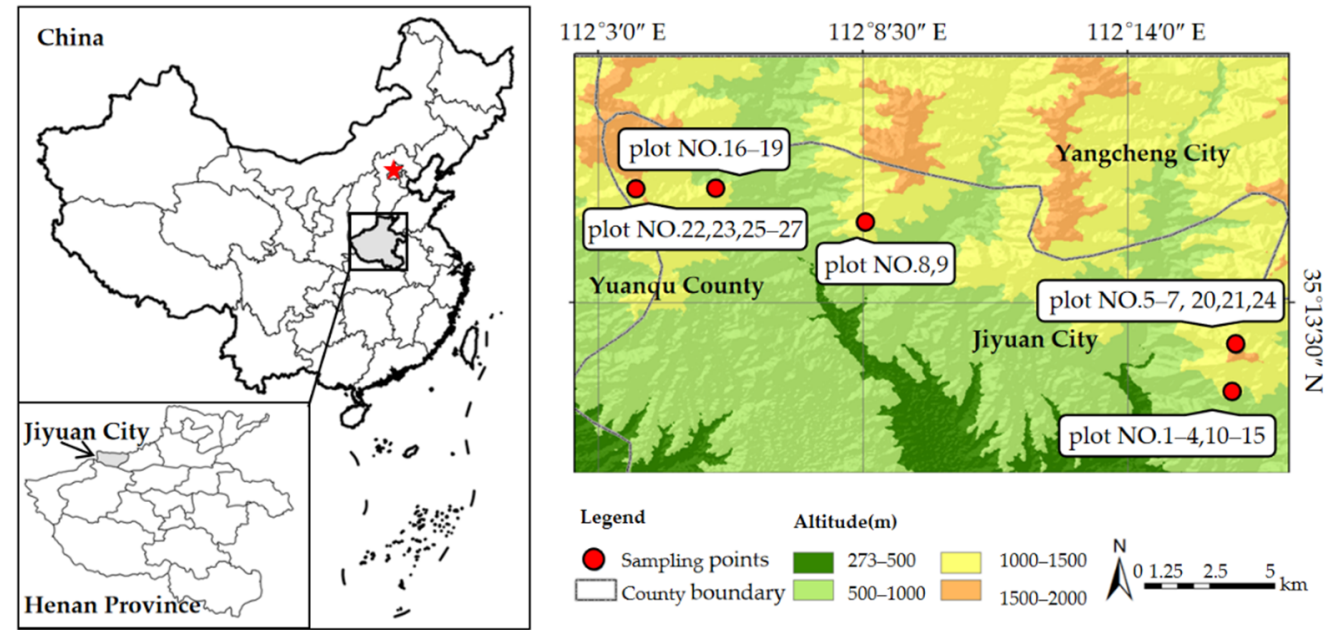

Figure 1. Location map of the sampling sites in northern Jiyuan City.

\subsection{Field Measurements}

A field survey was conducted in the Macaque Natural Reserve of Taihang Mountain in August 2020 in the southern Taihang Mountains. We selected the natural forest areas with typical characteristics and good growth as test objects from $700 \mathrm{~m}$ to $1900 \mathrm{~m}$, and then divided the survey area into three altitude areas: the lower altitude area (700-1100 m), medium altitude area (1100-1500 m), and higher altitude area (1500-1900 m). In each altitude area, 9 permanent $20 \times 20 \mathrm{~m}$ sample plots were established ( 27 in total). All trees with a diameter at breast height $(\mathrm{DBH} ; 1.3 \mathrm{~m}) \geq 1 \mathrm{~cm}$ were marked, and their locations in the plots were recorded using a forest locator (POSTEX). Meanwhile, we used hand-held GPS to measure the plots' locations and elevations. DBH, height, names, and growth of trees, canopy cover, slope aspect and the interference situation of the sample plots were also recorded (Table 1). Table 1 shows that the habitat conditions were similar among the nine sample plots under the same altitude area since it had a low degree of variation $(C V<15 \%)$ according to the basic indication information of trees and sample plots. 
Table 1. Basic information of the permanent samples.

\begin{tabular}{|c|c|c|c|c|c|c|c|}
\hline $\begin{array}{l}\text { Altitude } \\
\text { Zone }\end{array}$ & $\begin{array}{c}\text { Sample Plot } \\
\text { No. }\end{array}$ & $\begin{array}{l}\text { Mean DBH * } \\
(\mathrm{cm})\end{array}$ & $\begin{array}{l}\text { Mean Tree } \\
\text { Height (m) }\end{array}$ & $\begin{array}{l}\text { Tree Density } \\
\left(\text { Tree } / \mathrm{hm}^{2}\right)\end{array}$ & $\begin{array}{l}\text { Canopy } \\
\text { Density }\end{array}$ & Slope $\left({ }^{\circ}\right)$ & $\begin{array}{c}\text { Elevation } \\
\text { (m) }\end{array}$ \\
\hline \multirow{11}{*}{$\begin{array}{l}\text { Lower } \\
\text { altitude area }\end{array}$} & 1 & 10.44 & 5.99 & 3750 & 0.80 & 29 & 787 \\
\hline & 2 & 9.99 & 6.90 & 3975 & 0.75 & 32 & 852 \\
\hline & 3 & 10.76 & 6.63 & 4025 & 0.70 & 25 & 868 \\
\hline & 4 & 10.94 & 7.44 & 3625 & 0.78 & 23 & 871 \\
\hline & 5 & 12.70 & 7.14 & 3925 & 0.75 & 22 & 955 \\
\hline & 6 & 8.92 & 5.10 & 4050 & 0.80 & 31 & 971 \\
\hline & 7 & 11.37 & 6.41 & 3950 & 0.70 & 30 & 1016 \\
\hline & 8 & 10.41 & 6.74 & 4050 & 0.65 & 32 & 1054 \\
\hline & 9 & 12.32 & 7.58 & 4150 & 0.75 & 30 & 1066 \\
\hline & $\mathrm{CV}$ & 10.03 & 10.85 & 3.89 & 6.41 & 12.91 & 9.86 \\
\hline & 10 & 14.72 & 6.33 & 3225 & 0.65 & 24 & 1114 \\
\hline \multirow{9}{*}{$\begin{array}{l}\text { Medium } \\
\text { altitude area }\end{array}$} & 11 & 12.83 & 9.45 & 3375 & 0.65 & 25 & 1145 \\
\hline & 12 & 14.34 & 7.71 & 3150 & 0.68 & 30 & 1193 \\
\hline & 13 & 15.79 & 10.32 & 3375 & 0.65 & 30 & 1222 \\
\hline & 14 & 12.86 & 7.52 & 3600 & 0.70 & 25 & 1321 \\
\hline & 15 & 10.68 & 8.58 & 3900 & 0.78 & 28 & 1324 \\
\hline & 16 & 11.31 & 8.46 & 3175 & 0.80 & 32 & 1415 \\
\hline & 17 & 14.21 & 9.00 & 3325 & 0.80 & 26 & 1430 \\
\hline & 18 & 9.73 & 7.66 & 3475 & 0.75 & 35 & 1495 \\
\hline & $\mathrm{CV}$ & 14.79 & 13.40 & 6.55 & 8.56 & 12.34 & 9.80 \\
\hline \multirow{10}{*}{$\begin{array}{c}\text { Higher } \\
\text { altitude area }\end{array}$} & 19 & 11.94 & 8.97 & 4825 & 0.75 & 31 & 1510 \\
\hline & 20 & 8.94 & 8.23 & 4875 & 0.80 & 25 & 1521 \\
\hline & 21 & 11.29 & 7.31 & 4650 & 0.85 & 25 & 1535 \\
\hline & 22 & 11.82 & 8.16 & 4750 & 0.70 & 25 & 1539 \\
\hline & 23 & 12.97 & 8.12 & 4950 & 0.65 & 33 & 1554 \\
\hline & 24 & 12.80 & 8.06 & 4825 & 0.70 & 36 & 1582 \\
\hline & 25 & 10.75 & 8.97 & 4775 & 0.85 & 28 & 1720 \\
\hline & 26 & 9.86 & 8.49 & 4850 & 0.85 & 23 & 1787 \\
\hline & 27 & 10.31 & 8.29 & 4950 & 0.85 & 30 & 1813 \\
\hline & $\mathrm{CV}$ & 11.36 & 5.73 & 1.87 & 9.64 & 14.46 & 7.03 \\
\hline
\end{tabular}

${ }^{*}$ DBH: diameter at breast height (forestry).

\subsection{Data Analysis}

\subsubsection{Importance Values}

The importance value (IV) of a species was used to characterize the status and role of each species in the community and defined as the average of the relative abundance (RA), relative frequency $(R F)$ and relative dominance $(R D)$ of the species $[4,6]$. In this study, the IV was used as an index for selecting the dominant tree species. It was calculated with the following equations [6]:

$$
\begin{gathered}
\mathrm{IV}=(\mathrm{RA}+\mathrm{RD}+\mathrm{RF}) / 3 \\
\mathrm{RA}=a_{i} / \sum_{i=1}^{S} a_{i} \quad \mathrm{RD}=d_{i} / \sum_{i=1}^{S} d_{i} \quad \mathrm{RF}=f_{i} / \sum_{i=1}^{S} f_{i}
\end{gathered}
$$

where $a_{i}$ is the number of individuals of population $i, d_{i}$ is the basal area at the height of $1.3 \mathrm{~m}$ of population $i, f_{i}$ is the number of quadrats in which the population $i$ appears and $S$ is the total number of species.

\subsubsection{Interspecific Association Quantification}

The variance ratio $(V R)$ test was used to gain insight into the overall association among the different species, and significance was further tested using the $W$ statistic value. The formulas are listed below [31,32]:

$$
P_{i}=n_{i} / N
$$




$$
\begin{gathered}
V R=S_{T}^{2} / \delta_{T}^{2}=\left[\frac{1}{N} \sum_{i=1}^{N}\left(T_{j}-t\right)^{2}\right] / \sum_{i=n}^{S} P_{i}\left(1-P_{i}\right) \\
W=V R \times N
\end{gathered}
$$

where $n_{i}$ is the number of quadrats containing species $i, N$ is the total number of quadrats, $S$ is the total number of species, $T_{j}$ is the number of species occurring in quadrat $j$, and $t$ is the average number of species in the quadrats.

If $V R>1$, the species have a positive association, and if $V R<1$, species have a negative association. $V R=1$ indicates that species have no associations because they are assumed independent. If $\chi_{0.95(N)}^{2}<W<\chi_{0.05(N)}^{2}$, the overall interspecific association is not significant $(P>0.05)$. Conversely, the association is significant $(P<0.05)$ when $W<\chi_{0.95(N)}^{2}$ or $W>\chi_{0.05(N)}^{2}$.

The degree of association was conducted based on a $2 \times 2$ contingency column table that was generated by the existence or absence of the two species. For each pair of species $\mathrm{A}$ and $\mathrm{B}$, we can obtain a contingency table such as in the example of Table 2 [6]:

Table 2. Example of a $2 \times 2$ contingency table.

\begin{tabular}{ccccc}
\hline & & \multicolumn{2}{c}{ Species B } & \multirow{2}{*}{ Sum } \\
\cline { 3 - 4 } & & Present & Absent & \\
\hline \multirow{2}{*}{ Species A } & Present & $a$ & $b$ & $a+b$ \\
& Absent & $c$ & $d$ & $c+d$ \\
& Sum & $a+c$ & $b+d$ & $N=a+b+c+d$ \\
\hline
\end{tabular}

$a$, the number of quadrats in which species $\mathrm{A}$ and $\mathrm{B}$ co-occurred; $b$, the number of quadrats in which species $\mathrm{A}$ occurred, but not $B ; c$, the number of quadrats in which species $B$ occurred, but not $A ; d$, the number of quadrats in which neither A nor B were found; $N$, the total number of quadrats.

$\chi^{2}$ was corrected by the Yates continuous correction formula since the study was a discontinuous sample, and we determined the sign of the association between species pairs by the sign of the $V$ value $[33,34]$. The $b$ and $d$ values were weighted to 1 to avoid a non-computable situation when the denominator was 0 and the frequency of occurrence of a certain species was $100 \%$ [35]. These were calculated as follows:

$$
\begin{gathered}
\chi^{2}=N\left(|a d-b c|-\frac{1}{2} n\right)^{2} /[(a+b)(c+d)(a+c)(b+d)] \\
V=[(a+d)-(b+c)] /(a+b+c+d)
\end{gathered}
$$

When $\chi^{2}<3.841$, there is an insignificant interspecific association between two species pairs $(P>0.05)$, when $3.841 \leq \chi^{2} \leq 6.635$, the interspecific association between two species pairs is significant $(0.01 \leq P \leq 0.05)$ and when $\chi^{2}>6.635$, the interspecific association between two species pairs is highly significant $(P<0.01)$. In addition, if $V>0$, there is a positive association. Conversely, if $V<0$, there is a negative association [33].

The $\chi^{2}$ test results were further verified by the association coefficient $(A C)$ and the percentage of co-occurrence $(P C)$. The association coefficient $(A C)$ was used to quantify the interspecific association of each species pair, and the percentage of co-occurrence $(P C)$ can further reflect the strength of the positive association between tree species. These formulas are as follows:

$$
\begin{gathered}
\text { When } a d \geq b c, A C=(a d-b c) /[(a+b)(b+d)] \\
\text { When } a d<b c \text { and } d \geq a, A C=(a d-b c) /[(a+b)(a+c)] \\
\text { When } a d<b c \text { and } d<a, A C=(a d-b c) /[(b+d)(d+c)] \\
P C=a /(a+b+c)
\end{gathered}
$$

$A C$ index values range from 1 for complete positive associations $(b=0$ and $c=0)$ to -1 for complete negative associations ( $a=0$ and $d=0$ ). When $A C$ equals zero, it shows 
there is no association [6]. The $P C$ range is $(0,1)$. The closer the $P C$ is to 1 , the more positive associations between tree species pairs; when the $P C$ is equal to 0 , there is no association between the tree species pairs [35].

\subsubsection{Community Stability Analysis}

The Godron stability index was used to determine the community stability. The 27 plots with size of $20 \times 20 \mathrm{~m}$ were taken as a unit and arranged using the frequencies of all tree species in an ascending order. Next, the relative frequency of each tree species was calculated (the frequency of each species/the total frequency of all species), as well as the reciprocal of total species (1/the number of all species), its accumulative relative frequency (as dependent variable) and the accumulative reciprocal one by one (as an independent variable). Finally, using the smooth curve of scatter points, the binomial equation was simulated, and the coordinate of the intersection point between this simulation equation and the equation $y=-x+100$ was calculated. According to the Godron stability judgment method, the closer a coordinate is to the community stability point coordinate $(20,80)$, the higher the community stability is [36].

\subsection{Statistics and Analysis}

In this study, R 4.0.3 (R Core Team, Vienna, Austria), Excel 2016 (Microsoft Corporation, Redmond, WA, USA) and Origin 2018 (OriginLab, Northampton, MA, USA) were used for all statistical analyses. The species association indices were conducted using the $\mathrm{R}$ packages "spaa" [37] and "corrplot" [38]. The calculation and drawing of community stability were derived by Excel 2016 and Origin 2018, respectively. In addition, ArcGIS 10.2 was used to generate the map of the sampling plots.

\section{Results}

\subsection{Composition of Trees Species}

A total of 68 different tree species were found during our investigation in this field, with 23 tree species in the lower altitude area, 22 tree species in the medium altitude area, and 23 tree species in higher altitude area. Only 10 (14.71\%) tree species existed in all three altitude areas, and 24 (35.29\%) tree species only appeared in one altitude area, which indicated that there was an obvious difference in tree species composition in the different altitude areas. In this study, 21 dominant species with more than one frequency and importance values greater than $1 \%$ were selected for interspecific association analysis among the plant communities in the 3 different altitude areas (Table 3).

Table 3. Dominant species, abbreviations, and importance values.

\begin{tabular}{ccccc}
\hline \multirow{2}{*}{ Species } & Abbreviation & \multicolumn{3}{c}{ Importance Value/\% } \\
\cline { 3 - 5 } & & $\begin{array}{c}\text { Lower } \\
\text { Altitude Area }\end{array}$ & $\begin{array}{c}\text { Medium } \\
\text { Altitude Area }\end{array}$ & $\begin{array}{c}\text { Higher } \\
\text { Altitude Area }\end{array}$ \\
\hline Quercus aliena & $\mathrm{Qa}$ & 26.56 & 27.45 & 22.05 \\
Quercus variabilis & $\mathrm{Qv}$ & 23.98 & 19.73 & 3.87 \\
Koelreuteria paniculata & $\mathrm{Kp}$ & 6.17 & $/ 1$ & $/ 2$ \\
Pinus tabuliformis & $\mathrm{Pt}$ & 5.47 & $/ 2$ & 13.45 \\
Acer mono & $\mathrm{Am}$ & 4.65 & 7.33 & 4.27 \\
Diospyros lotus & $\mathrm{Dl}$ & 4.36 & 1.81 & $/ 1$ \\
Carpinus cordata & $\mathrm{Co}$ & 3.27 & 9.71 & 5.58 \\
Cotinus coggygria & $\mathrm{Cc}$ & 3.16 & $/ 1$ & $/ 1$ \\
Cornus macrophylla & $\mathrm{Cm}$ & 3.04 & 3.45 & 1.19 \\
Crataegus pinnatifida & $\mathrm{Cp}$ & 2.31 & 3.93 & $/ 1$ \\
Ziziphus jujuba & $\mathrm{Zj}$ & 1.33 & $/ 1$ & 1 \\
Malus honanensis & $\mathrm{Mh}$ & 1.32 & $/ 2$ & 1.51 \\
Acer davidii & $\mathrm{Ad}$ & 1.18 & 8.47 & 4.53 \\
\hline Toxicodendron vernicifluum & $\mathrm{Tv}$ & 1.10 & 2.78 & \\
\hline
\end{tabular}


Table 3. Cont.

\begin{tabular}{ccccc}
\hline \multirow{2}{*}{ Species } & Abbreviation & \multicolumn{3}{c}{ Importance Value/\% } \\
\cline { 3 - 5 } & & $\begin{array}{c}\text { Lower } \\
\text { Altitude Area }\end{array}$ & $\begin{array}{c}\text { Medium } \\
\text { Altitude Area }\end{array}$ & $\begin{array}{c}\text { Higher } \\
\text { Altitude Area }\end{array}$ \\
\hline Fraxinus chinensis & $\mathrm{Fc}$ & $/ 1$ & 2.66 & 2.43 \\
Zelkova schneideriana & $\mathrm{Zs}$ & $/ 1$ & 2.19 & $/ 1$ \\
Quercus mongolica & $\mathrm{Qm}$ & $/ 1$ & 1.39 & 5.64 \\
Picrasma quassioides & $\mathrm{Pq}$ & $/ 2$ & 1.22 & $/ 1$ \\
Rhus chinensis & $\mathrm{Rc}$ & $/ 1$ & 1.84 & $/ 1$ \\
Betula platyphylla & $\mathrm{Bp}$ & $/ 1$ & $/ 1$ & 3.75 \\
Pinus armandii & $\mathrm{Pa}$ & $/ 1$ & $/ 1$ & 10.49 \\
\hline
\end{tabular}

${ }^{1}:$ The species does not occur in the altitude area ${ }^{2}:$ The species occurs in the altitude area with a frequency less than 1 and has an importance value less than or equal to $1 \%$.

\subsection{Overall Interspecific Association}

The overall interspecific association of the communities in three altitude areas is presented in Table 4 . The results showed that the communities in the lower and higher altitude areas both exhibited a negative association for $V R<1$ and were also insignificant when combined with $W$ statistics and the $\chi^{2}$ test. Conversely, the community in the medium altitude area indicated a positive association for $V R>1$, and the $\chi^{2}$ test result further revealed an insignificant overall interspecific association. This indicated that the tree populations in medium altitude areas maintained a relatively stable stage and appeared to exist in a mutually beneficial symbiotic relationship.

Table 4. Overall association among dominant tree species.

\begin{tabular}{ccccc}
\hline Altitude Zone & Variance Ratio $(V R)$ & Test Statistics $(W)$ & $\chi_{\left(\mathbf{0 . 9 5 , N )}, \chi_{(0.05, N)}^{2}\right.}^{2}$ & Test Results \\
\hline Lower altitude area & 0.79 & 7.15 & $3.325,16.92$ & Not a significant association \\
Medium altitude area & 1.48 & 13.34 & $3.325,16.92$ & Not a significant association \\
Higher altitude area & 0.81 & 7.36 & $3.325,16.92$ & Not a significant association \\
\hline
\end{tabular}

\subsection{Associations between Dominant Species Pairs}

\subsubsection{Test of Dominant Species Pair Associations}

A $\chi^{2}$ test determined the level of significance of dominant species pairs based on the $2 \times 2$ contingency table. The results demonstrated that among the dominant tree populations, the proportion of positive associations decreased slightly as altitude increased from the lower altitude area (58.24\%) to the medium altitude area $(54.95 \%)$ and the higher altitude area (51.28\%) (Figure 2). In the lower altitude area, there were no significantly associated pairs. In the medium altitude area, a significantly positively associated pair was Cornus macrophylla and Carpinus cordata $\left(\chi^{2}=5.41 ; 0.01<P<0.05\right)$, and a negatively associated pair was Zelkova schneideriana and Acer mono $\left(\chi^{2}=-4.14 ; 0.01<P<0.05\right)$. In the higher altitude area, there were five pairs that reached significant associations. Quercus mongolica and Acer mono $\left(\chi^{2}=5.06 ; 0.01<P<0.05\right)$ showed a significant positive association, while Pinus armandii and Quercus variabilis $\left(\chi^{2}=-5.06 ; 0.01<P<0.05\right)$, Cornus macrophylla and Carpinus cordata $\left(\chi^{2}=-4.14 ; 0.01<P<0.05\right)$, Quercus mongolica and Pinus tabuliformis $\left(\chi^{2}=-5.06 ; 0.01<P<0.05\right)$ and Acer mono and Pinus tabuliformis $\left(\chi^{2}=-5.06\right.$; $0.01<P<0.05)$ all showed negative associations. Overall, our results indicated that most of the pairs among the dominant tree populations were not significant associations. This indicated that most species pairs were weak associations for most species, and the distribution of tree species is independent. 


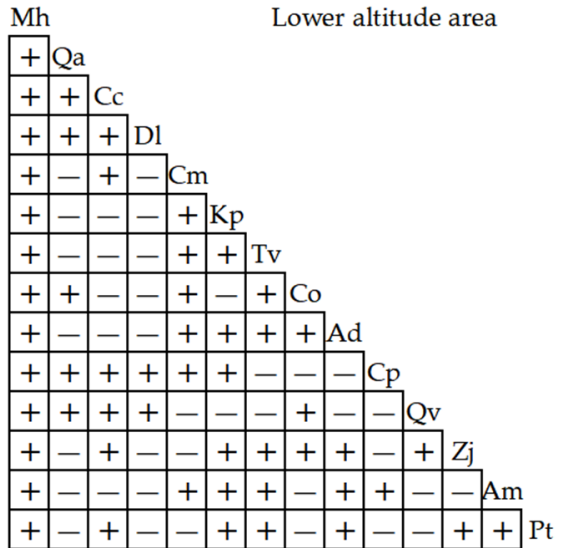

A Significantly positive association $\left(3.841 \leq \chi^{2}<6.635\right)$

$\Delta$ Significantly negative association $\left(3.841 \leq \chi^{2}<6.635\right)$
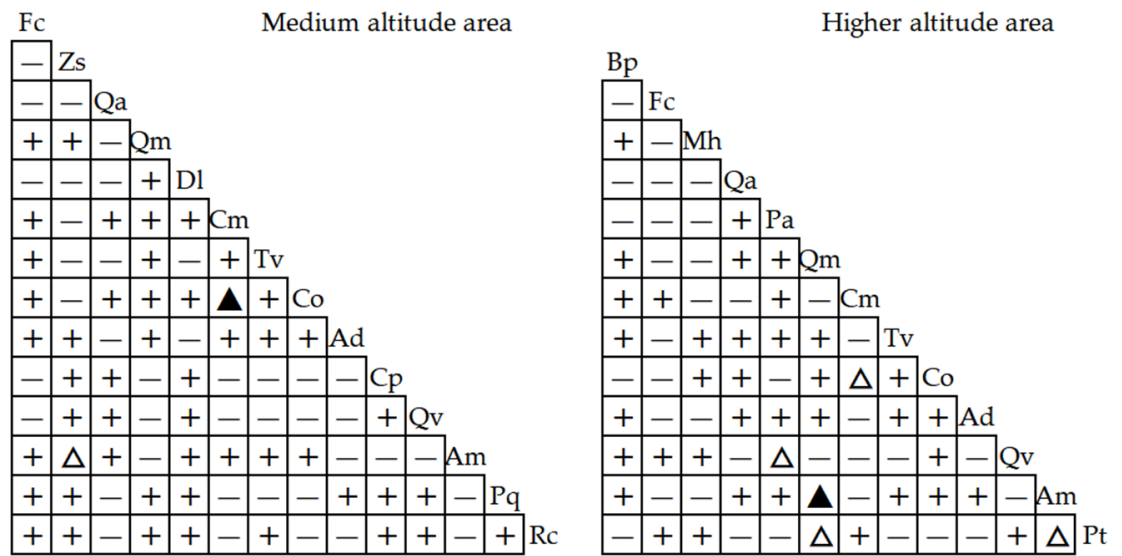

+ Not signicant positive association $\left(\chi^{2}<3.841\right)$

- Not signicant negative association $\left(\chi^{2}<3.841\right)$

Figure 2. Half matrix graph of the interspecific association $\chi^{2}$ test among the dominant tree species.

\subsubsection{Measures of Dominant Species Pair Associations}

The association coefficients $(A C)$ and the percentage of co-occurrence $(P C)$ results of the dominant tree species in the three altitude areas further distinguished the association strength between the species pairs (Figures 3-5 and Table 5). The number of positive association species pairs were 40,47 and 34 , with corresponding positive and negative species pair association ratio values of $0.78,1.07$ and 0.94 in the lower, medium and higher altitude areas, respectively, based on the $A C$ results.

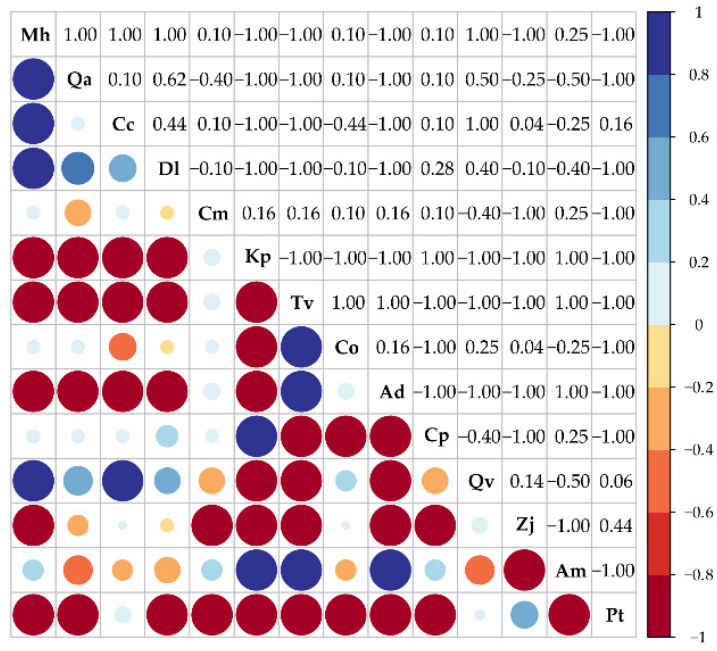

(a)

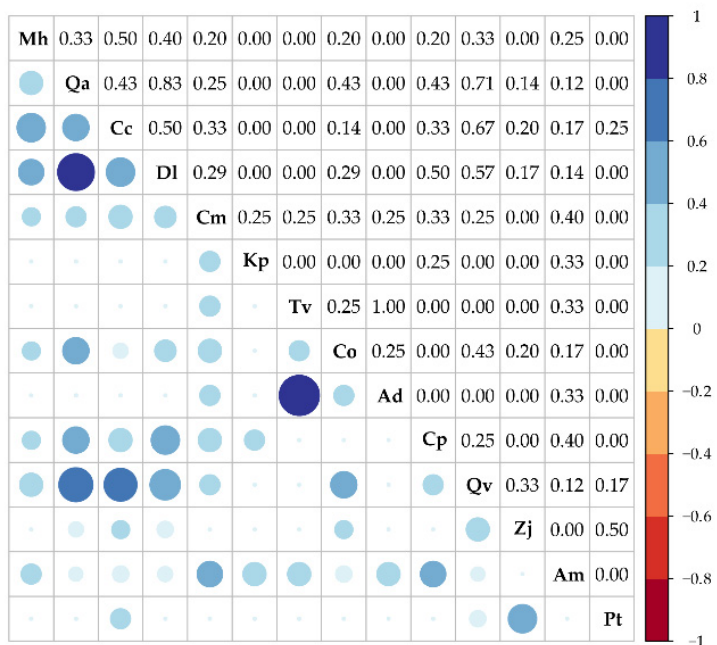

(b)

Figure 3. $A C$ and $P C$ values in lower altitude area: (a) the association coefficients ( $A C$ value); (b) the percentage of co-occurrence ( $P C$ value). Notes: The size and color depth of the circles represent the absolute value of the interspecific association. Blue represents a positive association between the tree pairs, and red represents a negative association between the tree pairs. The same below. 


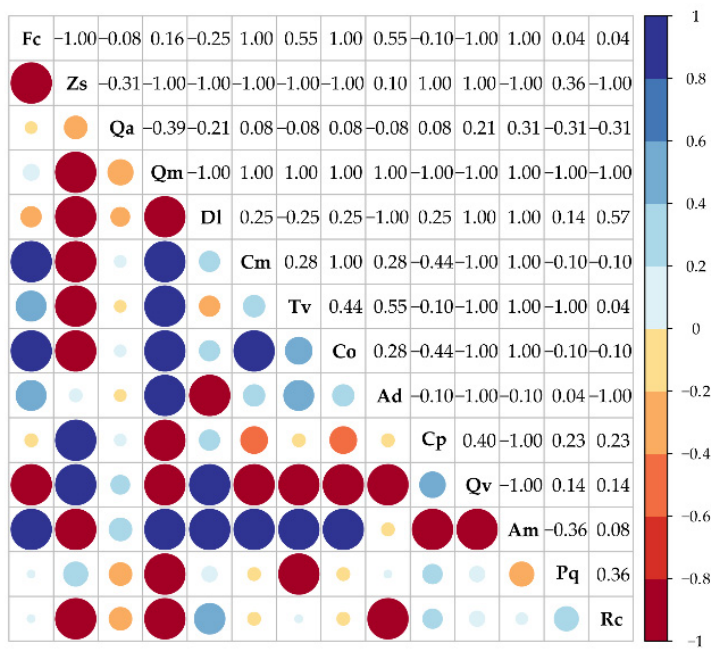

(a)

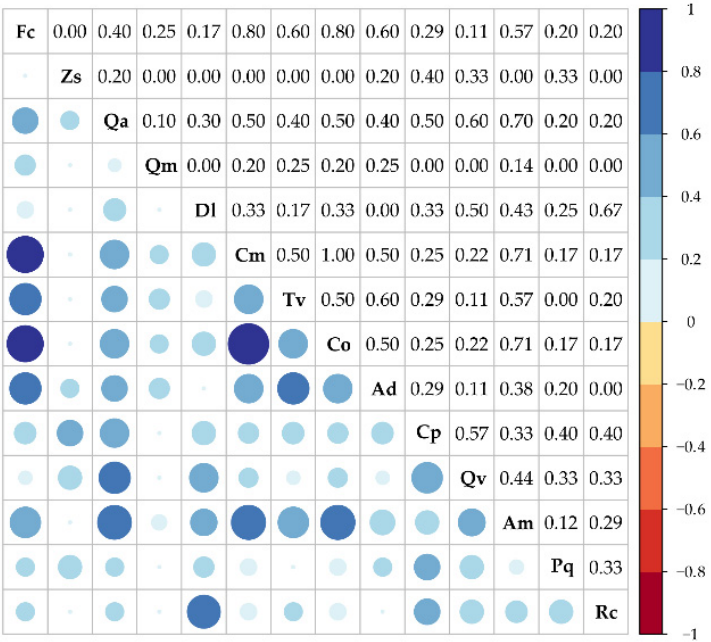

(b)

Figure 4. $A C$ and $P C$ values in the medium altitude area: (a) the association coefficients ( $A C$ value); (b) the percentage of co-occurrence ( $P C$ value).

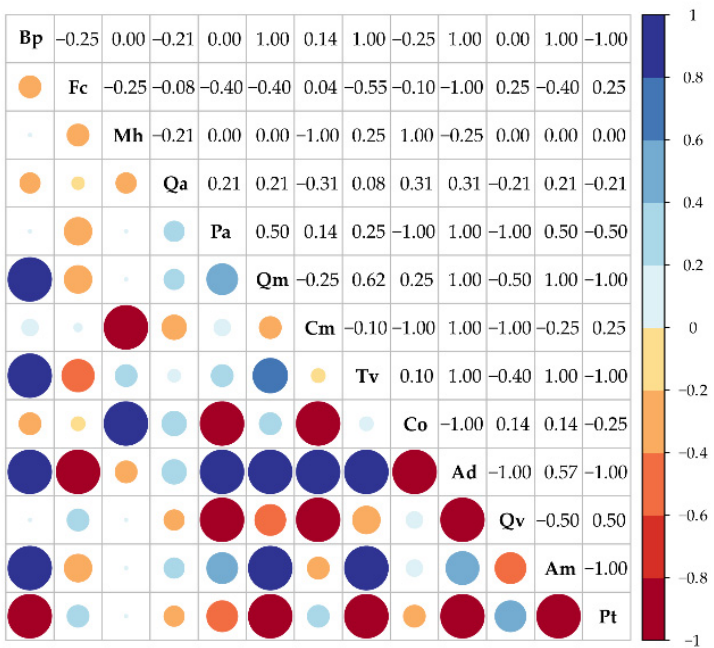

(a)

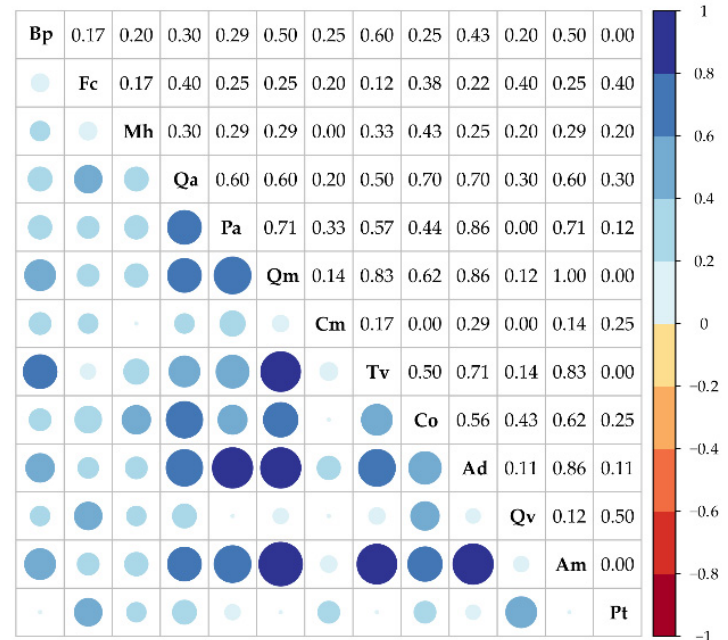

(b)

Figure 5. $A C$ and $P C$ values in the higher altitude area: (a) the association coefficients ( $A C$ value); (b) the percentage of co-occurrence ( $P C$ value).

In the lower altitude area, 12 species pairs showed obvious significant positive associations $(A C \geq 0.6)$, such as Quercus aliena and Diospyros lotus $(A C=0.62, P C=0.83)$, Malus honanensis and Quercus aliena $(A C=1.00, P C=0.33)$ and Toxicodendron vernicifluum and Acer davidii $(A C=1.00, P C=1.0)(A C=1.00, P C>0.25)$, indicating that these tree species were more likely to appear in the same habitats. Besides, there was an obvious significant negative association between 38 species pairs $(A C<-0.6)$, such as Pinus tabuliformis with other tree species $(A C=-1.00, P C=0)$ except for Quercus variabilis, Ziziphus jujuba and Cotinus coggygria, demonstrating no appearances in the same plots simultaneously. Additionally, there were 41 species pairs with weak associations $(-0.6 \leq A C<0.6)$. 
Table 5. The association coefficients and the percentage of co-occurrence among the dominant tree species.

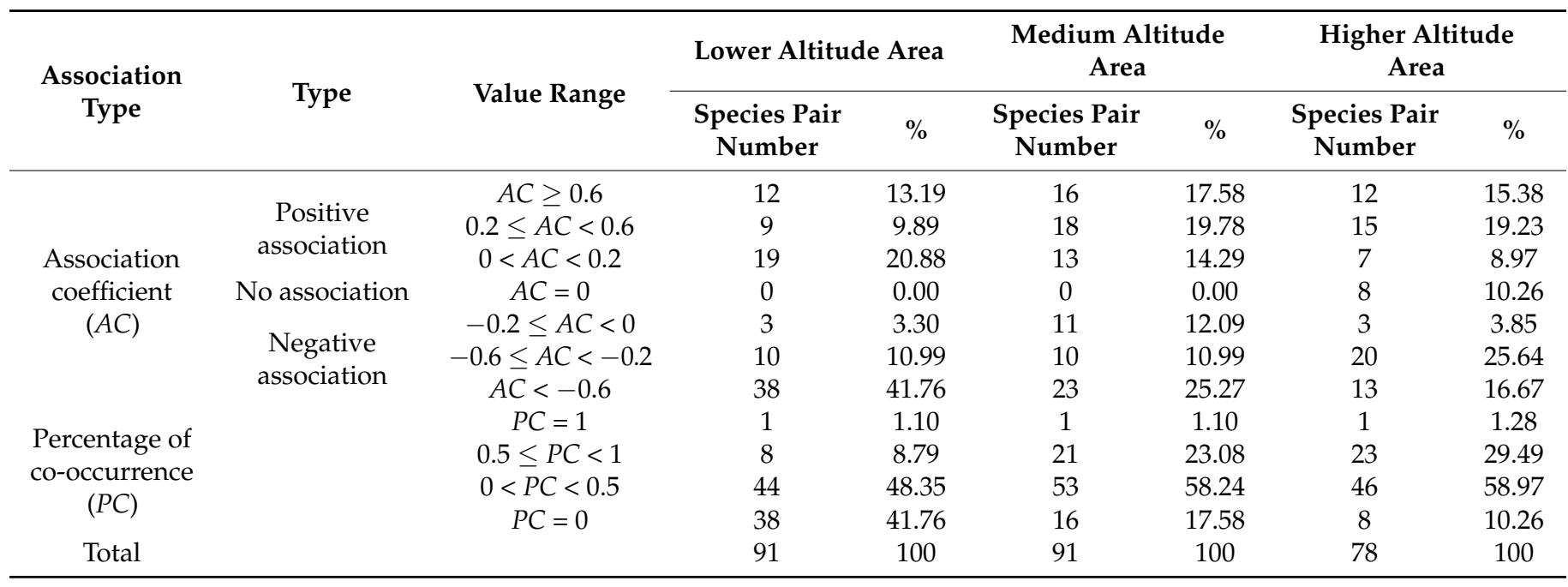

In the medium altitude area, there were 16 species pairs showing obvious significant positive associations $(A C \geq 0.6$ ), such as Acer mono and Carpinus cordata (Toxicodendron vernicifluum and Cornus macrophylla) $(A C=1.00, P C>0.5)$, suggesting a similar requirement for habitats. Apart from this, 23 species pairs showed obvious significant negative associations $(A C<-0.6)$, such as Quercus variabilis and Acer davidii (Carpinus cordata) $(A C=-1.00$, $P C<0.5)$. Moreover, 52 species pairs had unremarkable associations $(-0.6 \leq A C<0.6)$.

In the higher altitude area, 12 species pairs exhibited strong positive associations ( $A C \geq 0.6$ ), such as Acer davidii and Toxicodendron vernicifluum (Cornus macrophylla, Quercus mongolica, Pinus armandii and Betula platyphylla) $(A C=1.00)$, with corresponding larger $P C$ values. Conversely, 13 species pairs had strong negative associations $(A C \leq-0.6)$, such as Carpinus cordata and Acer davidii and Acer davidii and Quercus variabilis (AC $=-1)$, which meant there were large ecological differences among them. Besides, 53 species pairs were relatively weakly associated $(-0.6 \leq A C<0.6)$, and there were 8 species pairs that showed independent relationships among them $(A C=0)$, such as Malus honanensis and Pinus armandii (Quercus mongolica) $(A C=0, P C<0.5)$, which manifested completely independently and cannot appear in the same plots at the same time.

\subsection{Analysis of Community Stability in the Different Altitude Areas}

Godron scatter plots and the calculation results of communities in the three altitude areas are shown in Table 6 and Figure 6, respectively. The results showed that the distances from the intersection point of the three regression models to the stable point $(20,80)$ were $22.53,11.92,21.34$ in the lower, medium and higher altitude areas, respectively. According to the Godron stability judgment method, we can conclude that the medium altitude area had a more stable community compared with the other altitude areas.

Table 6. Community stability analysis results.

\begin{tabular}{ccccc}
\hline Altitude Area & Curve Equation & $\begin{array}{c}\text { Correlation } \\
\text { Coefficient }\end{array}$ & Coordinates & $\begin{array}{c}\text { Distance of Intersection } \\
\text { Point and Stable Point }\end{array}$ \\
\hline Lower altitude area & $\mathrm{y}=-0.0105 \mathrm{x}^{2}+1.9003 \mathrm{x}+9.3519$ & 0.982 & $35.93,64.07$ & 22.53 \\
Medium altitude area & $\mathrm{y}=-0.0104 \mathrm{x}^{2}+1.915 \mathrm{x}+8.7367$ & 0.995 & $28.43,71.57$ & 11.92 \\
Higher altitude area & $\mathrm{y}=-0.012 \mathrm{x}^{2}+2.0825 \mathrm{x}+6.6125$ & 0.992 & $35.09,64.91$ & 21.34 \\
\hline
\end{tabular}



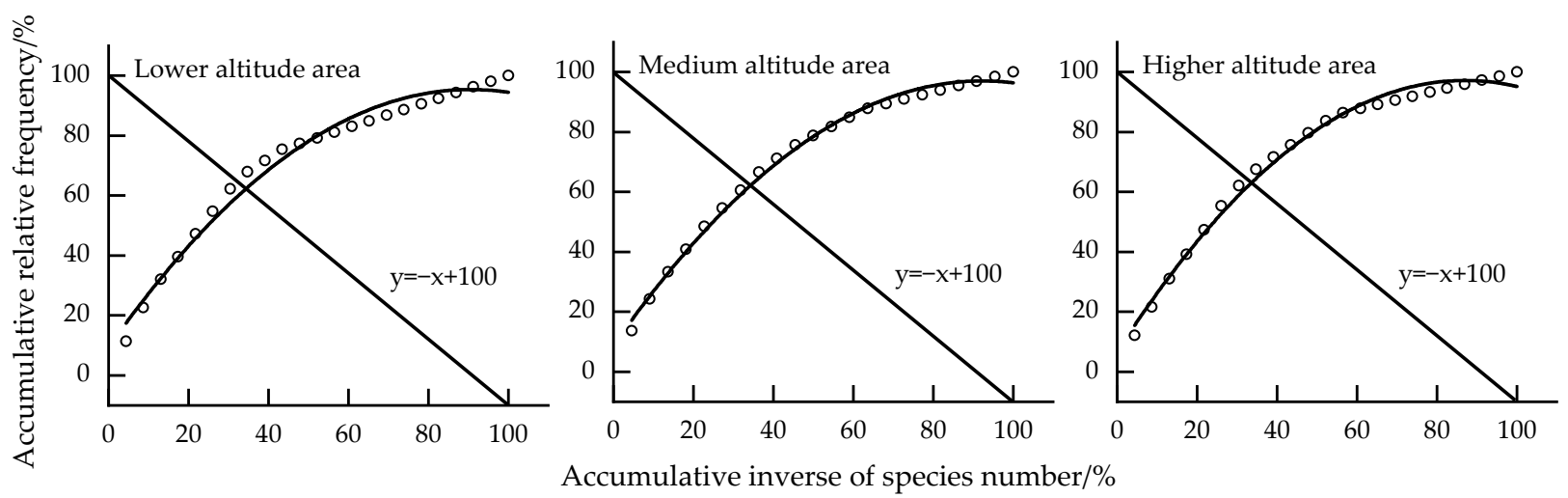

Figure 6. Godron scatter plots of communities in the three different altitude areas.

\section{Discussion}

\subsection{Analysis of Overall Interspecific Association}

The overall interspecific association reflects the stability of the community structure and species composition and better describes the community succession stage [39-41]. Generally, when a plant community reaches top-level succession, each species usually can achieve maximum utilization of the resource environment and can realize mutual promotion of species growth. Besides, the community structure tends to be complete and balanced [41-43], and, correspondingly, there is a positive overall species association. This means that when species show a negative interspecific association, the community was at an early succession or a secondary succession, with a relatively unstable community structure and composition and a low degree of interspecific association between species pairs. We calculated the overall interspecific association of the dominant species pairs at different altitude areas and found it was positive only in the medium altitude area, which suggested that, compared with other altitude areas, its community was in a stable phase, and the population of dominant trees appeared to exist in a mutually beneficial relationship.

\subsection{Analysis of the Associations among the Dominant Tree Species Pairs}

Interspecific associations represent a relationship among the species pairs in different habitats and show their ecological adaptability to environmental factors $[44,45]$. The $\chi^{2}$ test results showed that the ratio of positive and negative species pair associations appeared to have a downward trend as altitude increased, which, thus, illustrated a weakened correlation and interdependence among the tree populations. In fact, several significant positive species pair associations existed in the medium altitude area, so it seemed that the medium altitude area had a stronger association between the dominant species pairs, which was consistent with the result of overall interspecific association. However, it should be clearly recognized that the interspecific association was still loose, and the distribution of each tree species was relatively independent because most species pairs were not significantly associated.

A positive correlation between species pairs means that they have a same or similar demand for environmental resources and a reciprocal symbiotic relationship, while a negative correlation reflects the adaptability of species pairs to environmental heterogeneity due to their great differences in biological characteristics, thus resulting in an exclusion and niche separation [40,44-46]. For example, Carpinus cordata and Cornus macrophylla in the medium altitude area and Quercus Mongolica and Acer mono in the higher altitude area displayed a significant positive association because they are all fond of light and resistant to poor soil and cold environment, while Carpinus cordata and Cornus macrophylla in the higher altitude area displayed a significant negative association because, unlike Cornus macrophylla, Carpinus cordata is not resistant to water and humidity. However, the scale of habitats also had a great impact on the result of interspecies association. If the scale of habitats was too large, they mostly tended to have positive associations; otherwise, they had negative 
associations [47]. Generally, the appropriate area of a community in the temperate forest was $200-500 \mathrm{~m}^{2}$ according to the empirical value. In our study, the sample plot area was $400 \mathrm{~m}^{2}$, which was reasonable for the study, so we inferred that this biological characteristic was the key factor in interspecies association.

Similarly, the number of positive species pair associations was more than that of the negative associations only in the medium altitude area based on the AC and PC analyses, which is consistent with the overall interspecific association and the $\chi^{2}$ test. Moreover, the associations of some species pairs were not related to altitude change. For example, Quercus variabilis and Acer davidii were negatively associated throughout, while Toxicodendron vernicifluum and Carpinus cordata were positively associated from $700 \mathrm{~m}$ to $1900 \mathrm{~m}$. However, the associations of some species pairs evolved from positive to negative as altitude increased, such as Cornus macrophylla and Toxicodendron vernicifluum and Quercus aliena and Quercus variabilis, while some evolved from negative to positive, such as Quercus aliena and Acer davidii, which clarified that the altitude factor could surely change the associations between some species pairs.

The competition theory considered that the associations between species pairs would change due to external conditions, and a species pair may show different associations in different habitats [48,49], which confirmed the results of this study. The dominant species in the lower altitude area prefer sunshine and tend to compete for the limited light resources and nutrients, thus causing a negative association. Furthermore, forests in this area suffered from heavy logging activities in the last century and human interference in recent years. Therefore, it might change tree species composition, promote or inhibit the survival of certain tree species and have a certain negative impact on the interactions among species as well [50]. Moreover, our study showed that more positive species pair associations were observed than negative species pairs in the medium altitude area, owing to its better environmental conditions and protection, so we inferred that historical and realistic disturbances could affect the ratio of positive and negative associations. This was quite the same as the research results of $\mathrm{Gu}$ et al. [40]. Moreover, the number of negatively associated species was greater in the higher altitude area that was restricted by harsh climatic and soil conditions.

\subsection{Analysis of the Stability of Tree Communities}

The Godron method is comprehensive and systematic in describing community stability and can further improve the analysis results of interspecific association $[48,50]$. The Godron method analysis results in this study showed that the coordinates of the stability point change from $(35.93,64.07)$ in the lower altitude area to $(28.43,71.57)$ in the medium altitude area, and then to $(35.09,64.91)$ in the higher altitude area. It can be seen that the coordinate of stability point in medium altitude area was closer to the Godron stable point $(20,80)$ compared with the other altitude areas. This result is basically consistent with the results of $V R, A C$ and $P C$, because the lower altitude areas suffer from a certain human interference, and the habitat in higher altitude areas was inferior because of the lower temperature and poor soil fertility, which influence the status and role of the tree species in plant communities, thus affecting the community stability [21,22,44,51].

In summary, the communities in the southern foothills of the Taihang Mountains are at a relatively unstable succession stage, with fluctuating species compositions, community structures and competitions, though the community appeared to be steadier in medium altitude area, which was contrary to the results of Li et al. [52] on the interspecific association of the main trees in the tropical rainforest. The reason might be that tree species in the study areas are mainly oak trees, which are concentrated in the plot and more easily form dominant species groups and constructive tree species compared with tropical rain forests with complex community composition and high heterogeneity. 


\subsection{Vegetation Protection Strategy and Prospect}

In this study, we found that communities were at an unstable stage of secondary succession in this area, with Quercus aliena and Quercus variabilis as the main ones in the tree layers. These tree species had strong vitality, which distributed centrally and occupied a large part in community [28] Their niches were generally negatively associated with Fraxinus chinensis, Swida alba and other tree species, with an extremely small coupling coefficient and competitions for environmental resources. Therefore, we should not only fully understand the ecological and biological characteristics of tree species in the process of community reconstruction and restoration but also consider the influence of different habitats on the relationships between tree species. The specific measures are to select tree species with strong environmental adaptability and strong positive interspecific association according to the altitude division for collocation planting to improve the community structure, prevent vicious competition among species [53] and to promote the restoration of vegetation and the stability of communities in the southern Taihang Mountains.

Altitude could affect interspecies associations and community stability. However, it is still difficult to explain the specific reasons for the formation of interspecific associations, which are generally affected by complex factors. Therefore, the forest spatial structure index, soil, topography, climate and other factors should also be considered jointly to obtain a more comprehensive analysis result in future relevant research.

\section{Conclusions}

The overall interspecific association, association between dominant species pairs and community stability in natural secondary forests at different altitudes were studied in this research. We concluded that the altitude factor can change the interspecific associations between tree species pairs. The communities of three altitude areas were at a relatively unstable succession stage, though it was steadier in the medium altitude area. Tree species should be selected for planting in accordance with altitude gradients, and the ratio of positive and negative species pair correlations should also be adjusted reasonably. Studying the effects of the altitude factor on community stability and the interspecific association of natural secondary forest after long-term restoration is important to understand the effectiveness of ecosystem restoration in the local area.

Author Contributions: Methodology, S.-S.J. and Y.-Y.Z.; software, Y.-Y.Z. and M.-L.Z.; investigation, Y.-Y.Z., X.-M.D., C.-H.C. and T.W.; data curation, T.W., X.-M.D. and C.-H.C.; writing-original draft preparation, S.-S.J., Y.-Y.Z. and D.-F.Y.; writing-review and editing, Y.-Y.Z., S.-S.J. and M.-L.Z.; visualization, M.-L.Z. and S.-S.J.; project administration and funding acquisition, D.-F.Y. All authors have read and agreed to the published version of the manuscript.

Funding: This study was supported by Major Science and Technology Special Projects Research in Henan Province (Sub-project of Key Technologies for Cultivating High-efficiency and Stable Plantation in the Yellow River Basin Construction Technology of Stable Plant Community in Funiu Mountain Ecological Barrier Zone) (201300111400-2), and Science and Technology Projects Research in Henan Province (Key Carbon Sink Management Technologies for the Young and Middle-aged Oak Forests Based on Close to Nature Management) (222102110418).

Institutional Review Board Statement: Not applicable.

Informed Consent Statement: Not applicable.

Data Availability Statement: The following is available online at http://www.gscloud.cn/ (2 November 2021), Figure 1: Location map of the sampling sites in the northern Jiyuan City.

Acknowledgments: We are grateful to the staff from Yugong forest farm and Huanglianshu forest farm, Wang Qunxing and Sun Yijie from Henan Agricultural University for their support during fieldwork and Yu Xiaoya from Qiannan Normal University for Nationalities for his teaching in data processing.

Conflicts of Interest: The authors declare no conflict of interest. 


\section{References}

1. Liu, Y.Y.; Jin, G.Z. Spatial patterns and associations of four species in an old-growth temperate forest. J. Plant Interact. 2014, 9, 745-753. [CrossRef]

2. Luo, D.; Wang, C.S.; Dao, B.H.; Zhao, Z.G.; Guo, J.J.; Zeng, J. Species composition and diversity of Betula alnoides natural forests at Dehong Prefecture, Yunnan Province. For. Res. 2021, 34, 159-167.

3. Chen, Q.; Chen, J.; Zhong, J.J.; Ji, L.T.; Kang, B. Interspecific association and functional group classification of the dominant populations in shrub layer in secondary forest of Pinus tabuliformis in Qinling Mountain, China. Chin. J. Appl. Ecol. 2018, 29, $1736-1744$.

4. Liu, Z.W.; Zhu, Y.; Wang, J.J.; Ma, W.; Meng, J.H. Species association of the dominant tree species in an old-growth forest and implications for enrichment planting for the restoration of natural degraded forest in subtropical China. Forests 2019, 10, 957. [CrossRef]

5. Maihaiti, M.; Zhang, W.J. A mini review on theories and measures of interspecific associations. Selforganizology 2014, 1, 206-210.

6. Chai, Z.Z.; Sun, C.L.; Wang, D.X.; Liu, W. Interspecific associations of dominant tree populations in a virgin old-growth oak forest in the Qinling Mountains, China. Bot. Stud. 2016, 57, 23. [CrossRef] [PubMed]

7. Greig-Smith, P. Quantitative Plant Ecology; Blackwell Science Publications: Oxford, PA, USA, 1983; pp. 105-112.

8. Cole, L.C. The measure of interspecific association. Ecology 1949, 30, 411-424. [CrossRef]

9. Ofomata, V.C.; Overholt, W.A.; Van, H.A.; Egwuatu, R.I.; Ngi-Song, A.J. Niche overlap and interspecific association between Chilo partellus and Chilo orichalcociliellus on the Kenya coast. Entomol. Exp. Appl. 1999, 93, 141-148. [CrossRef]

10. Wang, B.S.; Li, M.G.; Zan, Q.J. An analysis of interspecific associations in secondary succession forest communities in Heishiding natural reserve, Guangdong Province. Chin. J. Plant Ecol. 2000, 24, 332-339.

11. Zhang, Z.H.; Hu, G. Interspecific relationships of dominant species in Cyclobalanopsis glauca community in karst mountain area Ecol. Env. Sci. 2011, 20, 1209-1213.

12. Lu, L.L.; Guo, Z.L.; Fan, C.N.; Zheng, J.P. Community characteristic and stability analysis of secondary deciduous broad-leaved forest in Mopan Mountains, Jilin Province, China. Chin. J. Appl. Ecol. 2018, 29, 2079-2087.

13. Yu, X.W.; Song, X.S.; Kang, F.F.; Han, H.R. Evaluation on the stability of typical forest community in source region of Liaohe river in North Hebei. J. Arid Land Res. Environ. 2015, 29, 93-98.

14. Hubalek, Z. Coeffident of association and similarity based on binary data: An evaluation. Biol. Rev. 1982, 57, 669-689. [CrossRef]

15. Zhang, Y.; Guo, L.P.; Yi, X.M.; Cao, W.; Wang, Y.X.; Wu, P.L.; Ji, L.Z. Analysis of interspecific associations among major tree species in three forest communities on the north slope of Changbai Mountain. Acta Ecol. Sin. 2015, 35, 0106-0115.

16. Jiang, H.; Zhang, H.; Long, W.X.; Fang, Y.S.; Fu, M.Q.; Zhu, K.X. Interspecific associations and niche characteristics of communities invaded by Decalobanthus boisianus. Biodivers. Sci. 2019, 27, 388-399.

17. Zhang, J.T.; Xi, Y.; Li, J. The relationships between environment and plant communities in the middle part of Taihang Mountain Range, North China. Community Ecol. 2006, 7, 155-163. [CrossRef]

18. Saha, S.; Rajwar, G.S.; Kumar, M. Forest structure, diversity and regeneration potential along altitudinal gradient in Dhanaulti of Garhwal Himalaya. For. Syst. 2016, 25, e058.

19. Tian, Z.P.; Wang, X.L.; Zhao, X.Y.; Zhuang, L. A unique mountains vertical distribution patterns and related environmental interpretation- a case on the northern slope of the ILI river valley. Pak. J. Bot. 2016, 48, 1877-1886.

20. Geng, S.B.; Shi, P.L.; Song, M.H.; Zong, N.; Zu, J.X.; Zhu, W.R. Diversity of vegetation composition enhances ecosystem stability along elevational gradients in the Taihang Mountains, China. Ecol. Indic. 2019, 104, 594-603. [CrossRef]

21. Mu, C.C.; Ni, Z.Y.; Li, D.; Chen, J.L. Distribution patterns of woody plant diversity in stream riparian forests along an altitudinal gradient in Changbai Mountains. Chin. J. Appl. Ecol. 2007, 18, 943-950.

22. Cabrera, O.; Benitez, A.; Cumbicus, N.; Naranjo, C.; Ramon, P.; Tinitana, F.; Escudero, A. Geomorphology and altitude effects on the diversity and structure of the vanishing montane forest of southern Ecuador. Diversity 2019, 11, 32. [CrossRef]

23. Bhutia, Y.; Gudasalamani, R.; Ganesan, R.; Saha, S. Assessing Forest structure and composition along the altitudinal gradient in the state of Sikkim, Eastern Himalayas, India. Forests 2019, 10, 633. [CrossRef]

24. Zhang, Y.B.; Meng, Q.X.; Qin, H.; Zhang, F. Flora and geographic pattern of mountain forests at community level in Taihang Mountains: Results based on plant community survey. J. Appl. Ecol. 2019, 30, 3395-3402.

25. Yang, X.L.; Xu, Q.H.; Zhao, H.P. The vegetation succession since the last glaciation in Taihang Mountains. Geogr. Territ. Res. 1999, $15,82-89$.

26. Zhao, H.; Wang, Q.R.; Fan, W.; Song, G.H. The relationship between secondary forest and environmental factors in the Southern Taihang Mountains. Sci. Rep. 2017, 7, 2474-2475. [CrossRef]

27. Wang, J.; Feng, J.W.; Niu, S.; Zhao, L.X.; Ye, Y.Z. Comparative analysis of niche characteristics of the species and interspecific correlation in Taihang Mountains. J. Henau Agric. Univ. 2016, 50, 181-188.

28. Yan, D.F.; Zhang, Y.Y.; Lv, K.T.; Zhou, M.L.; Wang, T.; Zhao, N. Niche characteristics of dominant tree species in natural forests at different altitudes in the south of Taihang Mountains. J. Ecol. Env. Sci. 2021, 30, 1571-1580.

29. Zhao, Y.; Fan, W.; Ye, Y.Z.; Yan, L.; Zhao, D. Analysis of species diversity of difference plant communities in hilly region of Taihang mountain. Sci. Soil Water Conser. 2007, 5, 64-71.

30. Wan, M.; Tian, D.L.; Wei, W. Structure characteristics of the Quercus variabilis forest community in the south area of Taihang Mountains. J. Henau Agric. Univ. 2009, 43, 139-144, 150. 
31. Schluter, D. A variance test for detecting species associations, with some example applications. Ecology 1984, 65, 998-1005. [CrossRef]

32. Shao, L.Y.; Zhang, G.F. Niche and interspecific of dominant tree populations of Zelkova Schneideriana community in eastern China. Bot. Sci. 2021, 99, 823-833. [CrossRef]

33. Dai, J.; Liu, H.; Xu, C.; Qi, Y.; Zhu, X.; Zhou, M.; Liu, B.; Wu, Y. Divergent hydraulic strategies explain the interspecific associations of co-occurring trees in forest-steppe ecotone. Forests 2020, 11, 942. [CrossRef]

34. Yarranton, G.A. A plotless method of sampling vegetation. J. Ecol. 1966, 54, 229-237. [CrossRef]

35. Wang, B.S.; Peng, S.L. Studies on the measuring techniques of interspecific association of lower-subtropical evergreen-broadleaved forests. Chin. J. Plant Ecol. 1985, 4, 274-285.

36. Godron, M. Some aspecets of heterogeneity in grasslands of Cantal. Statis. Ecol. 1972, 3, 397-415.

37. Zhang, J.L. Spaa: Species Association Analysis, R Package Version 0.2.2; R Foundation for Statistical Computing: Vienna, Austria, 2016.

38. Wei, T.; Simko, V.R. Package "Corrplot": Visualization of a Correlation Matrix (Version 0.84). Available online: https://github. com/taiyun/corrplot (accessed on 1 November 2021).

39. Su, S.J.; Liu, J.F.; He, Z.S.; Zheng, S.Q.; Hong, W.; Xu, D.W. Ecological species groups and interspecific association of dominant tree species in Daiyun Mountain National Nature Reserve. J. Mt. Sci. 2015, 12, 637-646. [CrossRef]

40. Gu, L.; Gong, Z.W.; Li, W.Z. Niches and interspecific associations of dominant populations in three changed stages of natural secondary forests on Loess Plateau, P.R. China. Sci. Rep. 2017, 7, 6604-6616. [PubMed]

41. Ma, F.F.; Pan, G.; Li, X.Q.; Han, Y.J. Interspecific relationship and canonical correspondence analysis within woody plant communities in the karst mountains of Southwest Guangxi, southern China. J. Beijing For. Univ. 2017, 39, 32-44.

42. Li, T.T.; Rong, L.; Wang, M.J.; Ye, T.M.; Qi, W. Dynamic changes in niche and interspecific association of major species of karst secondary forest in central Guizhou. J. Trop. Subtrop. Bot. 2021, 29, 9-19.

43. Jin, S.; Wu, S.K. Niche and interspecific association of dominant species in herb layer of burned Pinus tabuliformis forest in the southern Taihang Mountain of northern China. J. Beijing For. Univ. 2021, 43, 35-46.

44. Liu, R.H.; Jiang, Y.; Chang, B.; Li, J.F.; Rong, C.Y.; Liang, S.C.; Yang, R.A.; Liu, X.T.; Zeng, H.F.; Su, X.L.; et al. Interspecific associations and correlations among the main woody plants in a Pterocarya stenoptera community in a riparian zone of Lijiang River, Guilin, Southwest China. Acta Ecol. Sin. 2018, 38, 6881-6893.

45. Wu, D.T.; Wu, C.P.; Sheng, G.; Wei, X.; Jiao, J.J.; Jiang, B.; Zhu, J.R.; Yuan, W.G. Interspecific association dynamics of Nanmu natural forest in Jiande, Zhejiang Province. J. Zhejiang AF Univ. 2021, 38, 671-681.

46. Lv, A.Q.; Li, D.H.; Yang, X.B.; Wu, L.X. Plant community diversity and inter-specific relationship of coastal rain forest, semideciduous monsoon forest to deciduous monsoon forest in coastal hills of Sanya City, Hainan Province. Guihaia 2021, 41, 384-395.

47. Xu, M.H.; Liu, M.; Zhai, D.T.; Liu, T. A review of contents and methods used to analyze various aspects of plant interspecific associations. Acta Ecol. Sin. 2016, 36, 8224-8233.

48. Liu, R.X.; Chen, L.Q. Effect of flooding disturbance on plant community stability and interspecific relationship in the riparian zone of reservoir. Acta Ecol. Sin. 2021, 41, 6566-6579.

49. Luo, J.F.; Zheng, J.M.; Zhou, J.X.; Zhang, X.; Cui, M. Analysis of the interspecific associations present in an alpine meadow community undergoing revegetation on the railway-construction affected land of the Qinghai-Tibet Plateau. Acta Ecol. Sin. 2016, $36,6528-6537$.

50. Xie, C.P.; Liu, D.W.; Nan, C.H.; Li, H.; Huang, C.Y.; Zhang, J. Study on community stability and interspecific correlations among dominant populations in Pseudolarix amabilis communities. Ecol. Sci. 2021, 40, 62-70.

51. Ye, Q.P.; Zhang, W.H.; Yu, S.C.; Xue, W.Y. Interspecific association of the main tree populations of the Quercus acutissima community in the Qiaoshan forest area. Acta Ecol. Sin. 2018, 38, 3165-3174.

52. Li, J.L.; Lin, Y.C.; Wang, X.; Liu, H.W.; Wen, G.S.; Wag, S.; Zhang, X.L. Comparative study on rainforest species association in different altitude in Mountain Diaoluo of Hainan. Chin. J. Trop. Crop. 2013, 34, 584-590.

53. Liu, R.H.; Chen, L.; Tu, H.R.; Liang, S.C.; Jiang, Y.; Li, Y.J.; Huang, D.L.; Nong, J.L. Niche and interspecific association of main species in shrub layer of Cyclobalanopsis glauca community in karst hills of Guilin, southwest China. Acta Ecol. Sin. 2020, 40, 2057-2071. 